\title{
Thermally switchable molecular upconversion emission
}

Giuseppina Massaro, ${ }^{\dagger}$ Jordi Hernando, ${ }^{\ddagger}$ Daniel Ruiz-Molina, ${ }^{\#}$ Claudio Roscini, ${ }^{,, \#}$ Loredana Latterini $^{*, \dagger}$

†Department of Chemistry, Biology and Biotechnology, Perugia University, Via Elce di sotto, 8, o6123, Perugia, Italy ‡Departament de Química, UniversitatAutònoma de Barcelona, Edifici C/n, Campus UAB, o8193 Cerdanyola del Vallès, Spain

\# Catalan Institute of Nanoscience and Nanotechnology (ICN2), CSIC and The Barcelona Institute of Science and Technology, 7 Campus UAB, Bellaterra, o8193 Barcelona, Spain

e-mail: loredana.latterini@unipg.it; croscini@cinz.es

\section{Contents}

S1. Supplementary figures S1-S19

S2. Supplementary methods

S3. Bibliography

S13 


\section{S1. Supplementary figures}

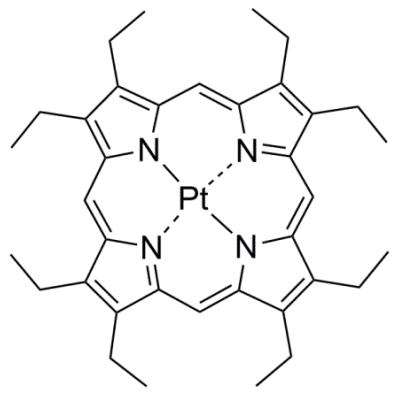

PtOEP<smiles>Oc1ccc(-c2c3ccccc3c(-c3ccccc3)c3ccccc23)cc1</smiles>

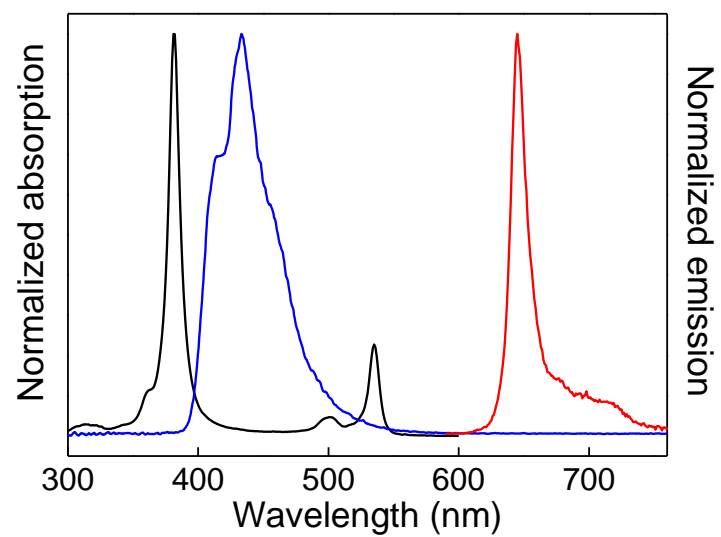

Figure S1. Chemical structures of UC PtOEP-DPA pair and normalized PtOEP absorption (black) and emission spectra of DPA (blue) and PtOEP (red) in toluene.
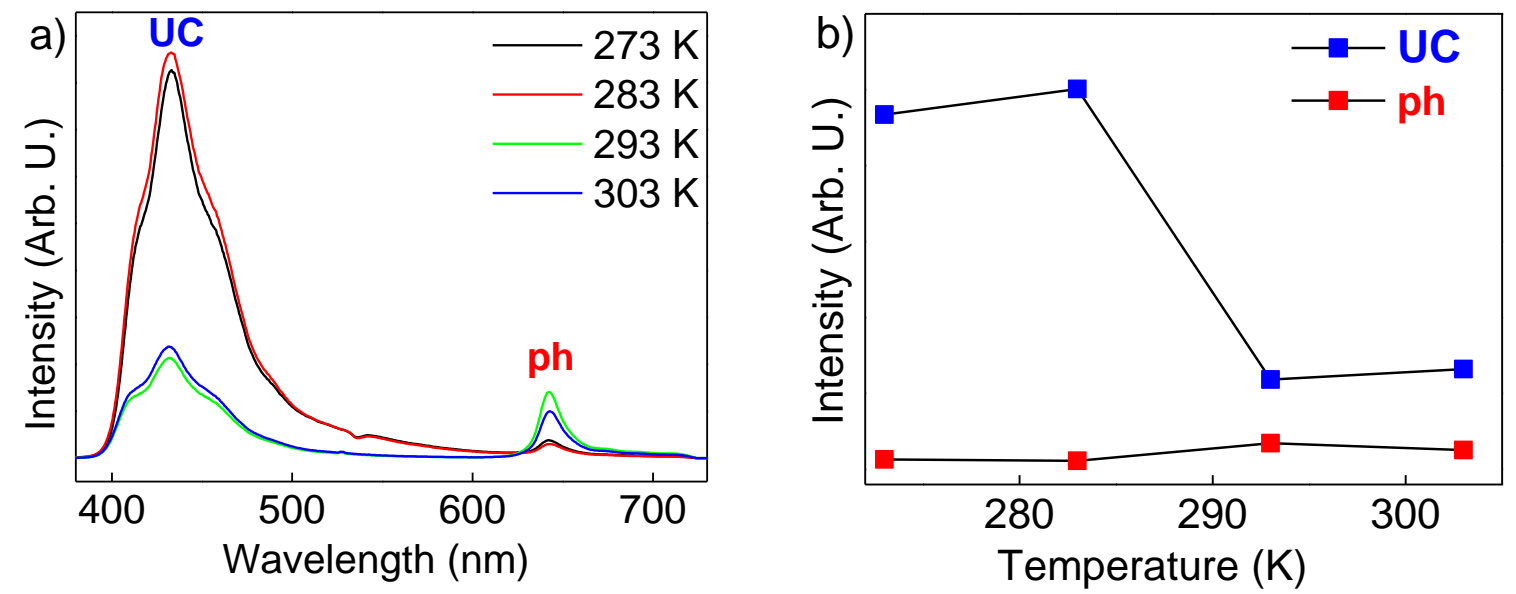

Figure S2. a) UC $\left(\lambda_{\max }=433 \mathrm{~nm}\right)$ and phosphorescence $(\mathrm{ph})$ emissions $\left(\lambda_{\max }=647 \mathrm{~nm}\right)$ of a PtOEP-DPA mixture in $\mathrm{HD}$ at different temperatures $([\mathrm{PtOEP}]=10 \mu \mathrm{M}$; $[\mathrm{DPA}]=300 \mu \mathrm{M})$. b) Integrated intensities of the UC and phosphorescence bands measured for this sample at different temperatures. 


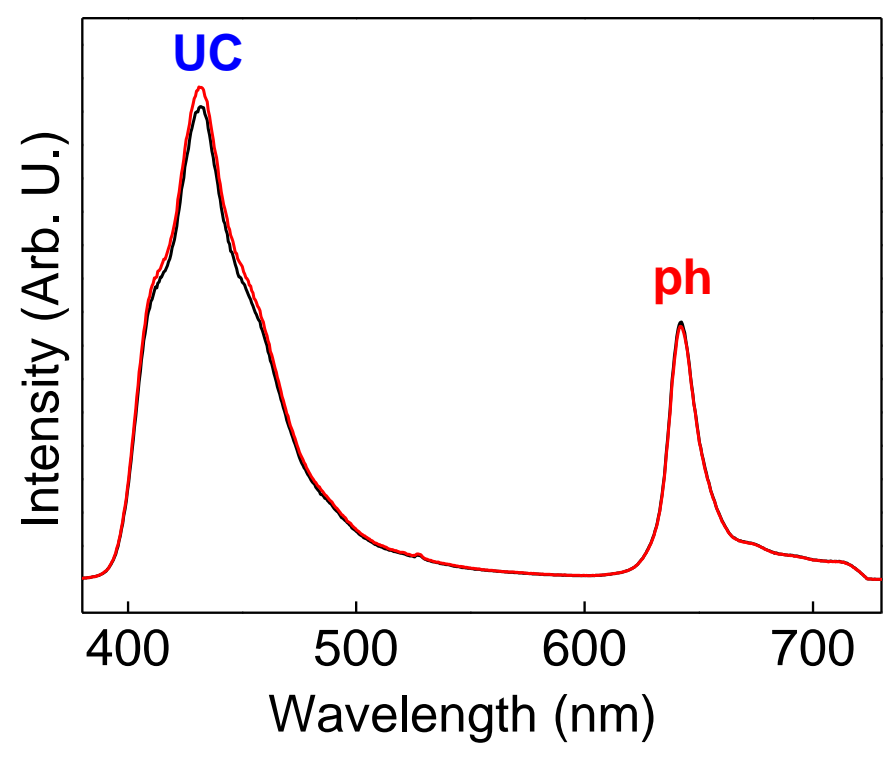

Figure S3. Comparison of the emission spectra of a PtOEP-DPA liquid solution in HD at $303 \mathrm{~K}([\mathrm{PtOEP}]=10 \mu \mathrm{M}$; $[\mathrm{DPA}]=300 \mu \mathrm{M})$ before (black line) and after (red line) a cooling-warming cycle. Clearly, both UC $\left(\lambda_{\max }=433 \mathrm{~nm}\right)$ and phosphorescence $\left(\lambda_{\max }=647 \mathrm{~nm}\right)$ bands recovered their initial intensities after undergoing a liquid-solid-liquid transition.
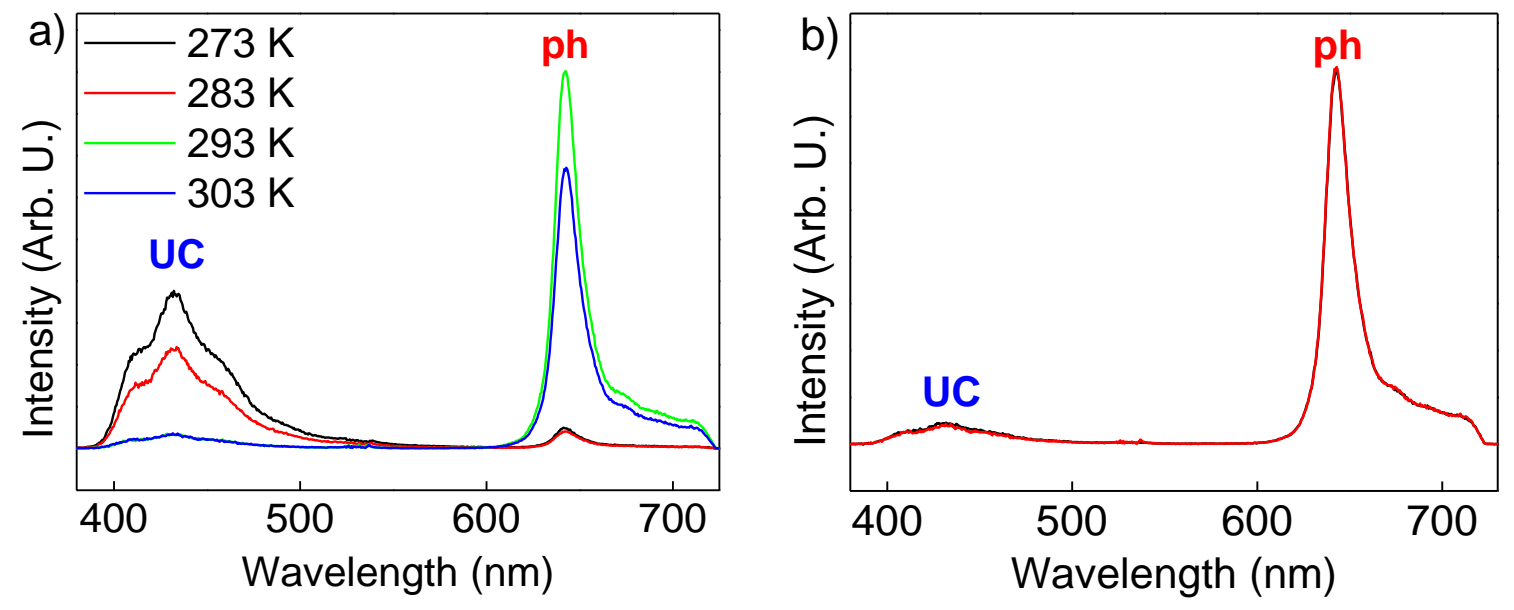

Figure S4. a) UC $\left(\lambda_{\max }=433 \mathrm{~nm}\right)$ and phosphorescence $\left(\lambda_{\max }=647 \mathrm{~nm}\right)$ emissions of a PtOEP-DPA mixture in HD at different temperatures $([\mathrm{PtOEP}]=1 \mu \mathrm{M} ;[\mathrm{DPA}]=30 \mu \mathrm{M})$. b) Comparison of the emission spectra of this sample at $303 \mathrm{~K}$ measured before (black line) and after (red line) a cooling-warming cycle. Both UC and phosphorescence bands recovered their initial intensities after the thermal treatment. 


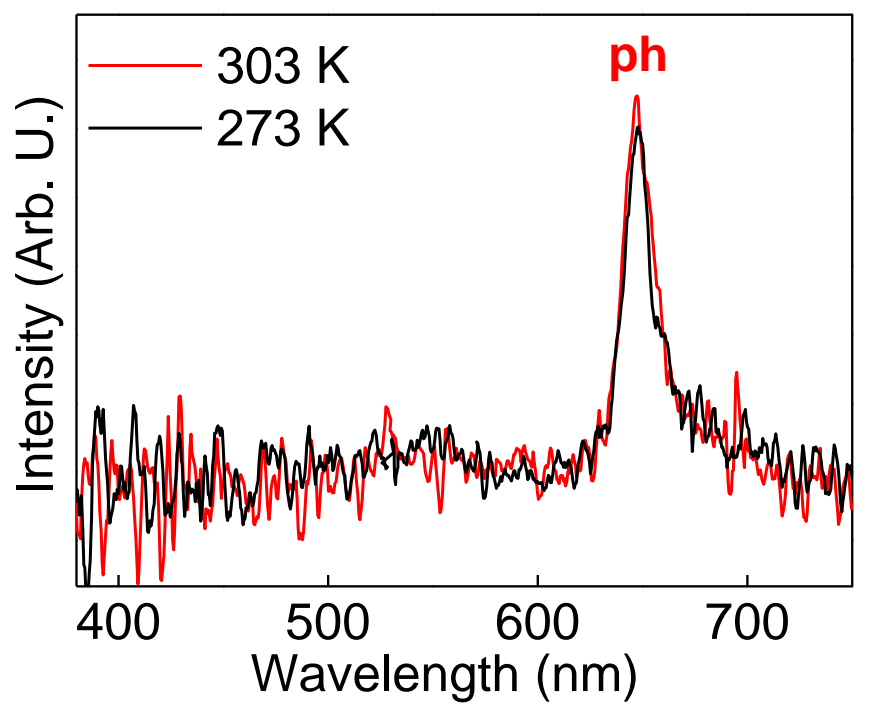

Figure S5. Emission spectra of an aerated PtOEP-DPA mixture $([\mathrm{PtOEP}]=1 \mu \mathrm{M}$; $[\mathrm{DPA}]=30 \mu \mathrm{M})$ in liquid $(\mathrm{T}=303$ $\mathrm{K})$ and solid $(\mathrm{T}=273 \mathrm{~K}) \mathrm{HD}$. No UC emission $\left(\lambda_{\max }=433 \mathrm{~nm}\right)$ was observed in either case, while only very dim phosphorescence $\left(\lambda_{\max }=647 \mathrm{~nm}\right)$ was registered.
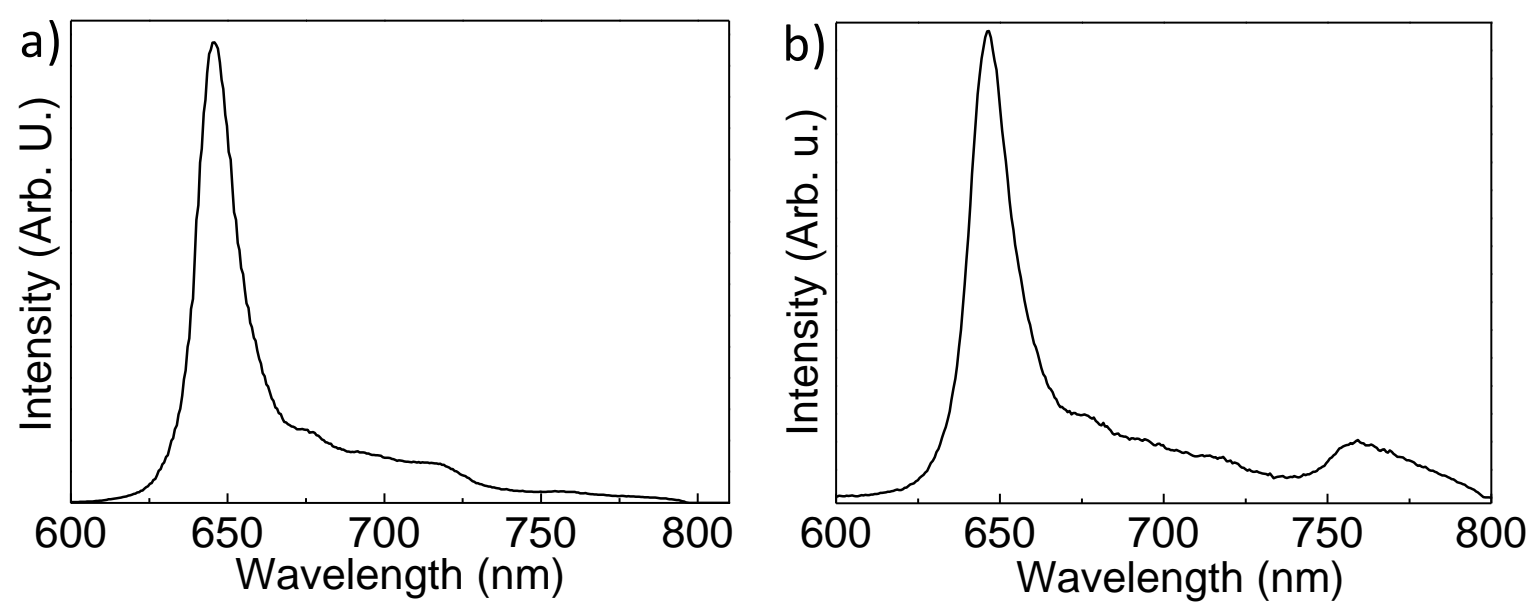

Figure S6. Emission spectra of a deaerated PtOEP solution $([\mathrm{PtOEP}]=1 \mu \mathrm{M})$ in a) liquid $(\mathrm{T}=293 \mathrm{~K})$ and $\mathrm{b})$ solid $(\mathrm{T}$ $=273 \mathrm{~K}) \mathrm{HD}$. 

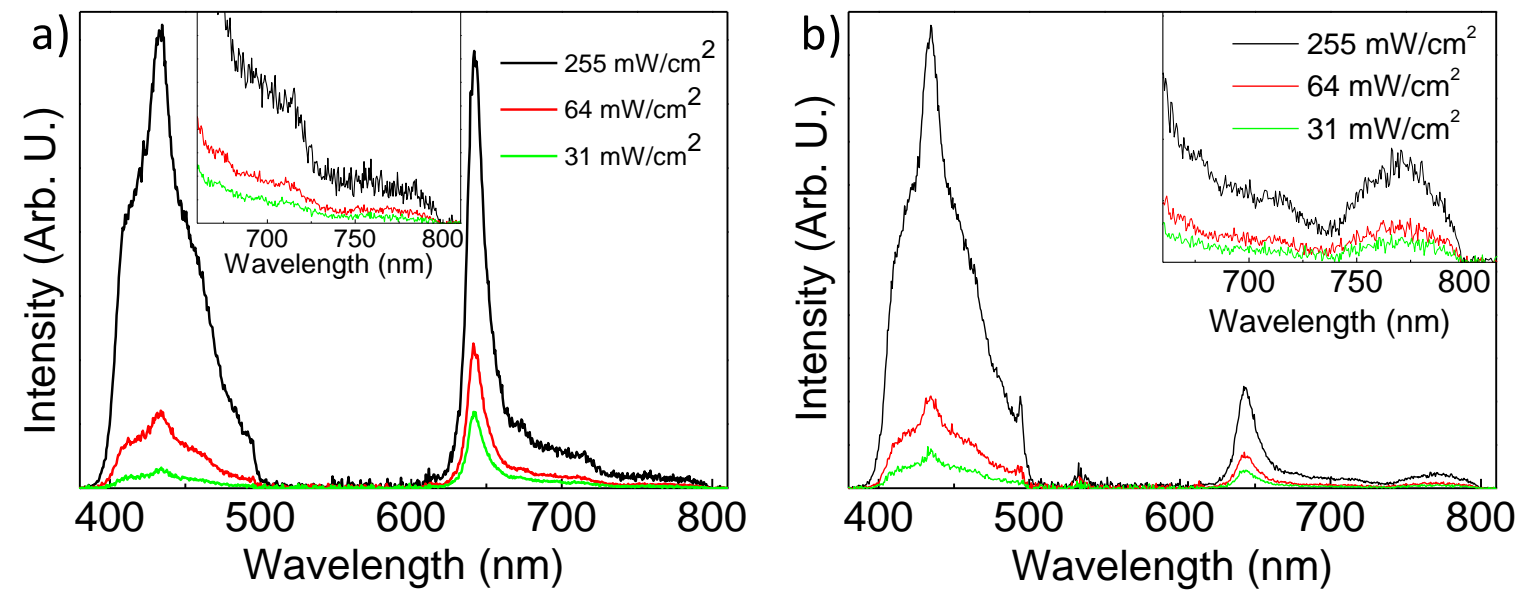

Figure S7. Emission spectra of a deaerated PtOEP-DPA mixture $([\mathrm{PtOEP}]=1 \mu \mathrm{M}$; $[\mathrm{DPA}]=30 \mu \mathrm{M})$ in a) liquid $(\mathrm{T}=$ $293 \mathrm{~K})$ and $\mathrm{b})$ solid $(\mathrm{T}=273 \mathrm{~K}) \mathrm{HD}$ at three different excitation power densities. In the respective insets there are the zooms of the spectra in the range of $650-800 \mathrm{~nm}$.

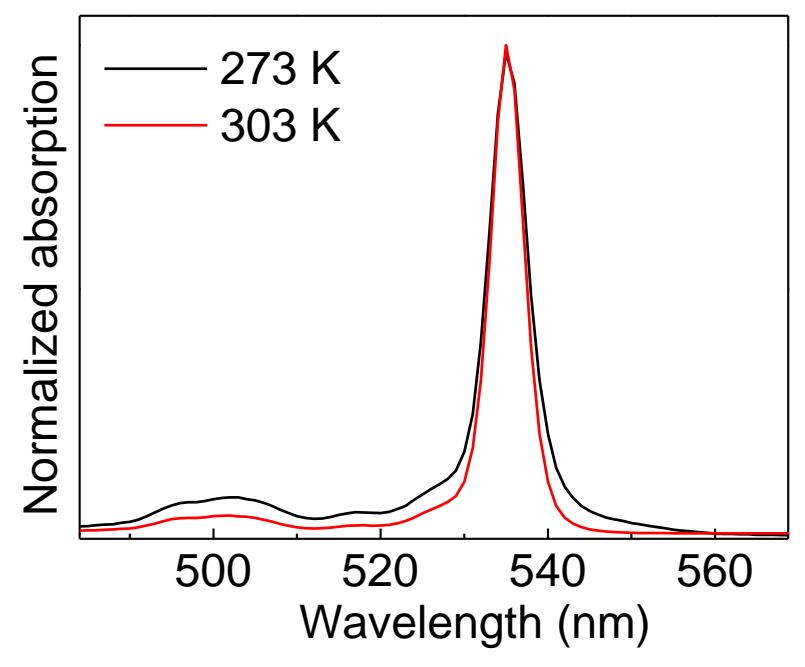

Figure S8. Section of the absorption spectrum of a PtOEP-DPA mixture $([\mathrm{PtOEP}]=10 \mu \mathrm{M},[\mathrm{DPA}]=300 \mu \mathrm{M})$ in liquid $(\mathrm{T}=293 \mathrm{~K})$ and solid $(\mathrm{T}=273 \mathrm{~K}) \mathrm{HD}$. The solid mixture was measured by using the integrating sphere. 

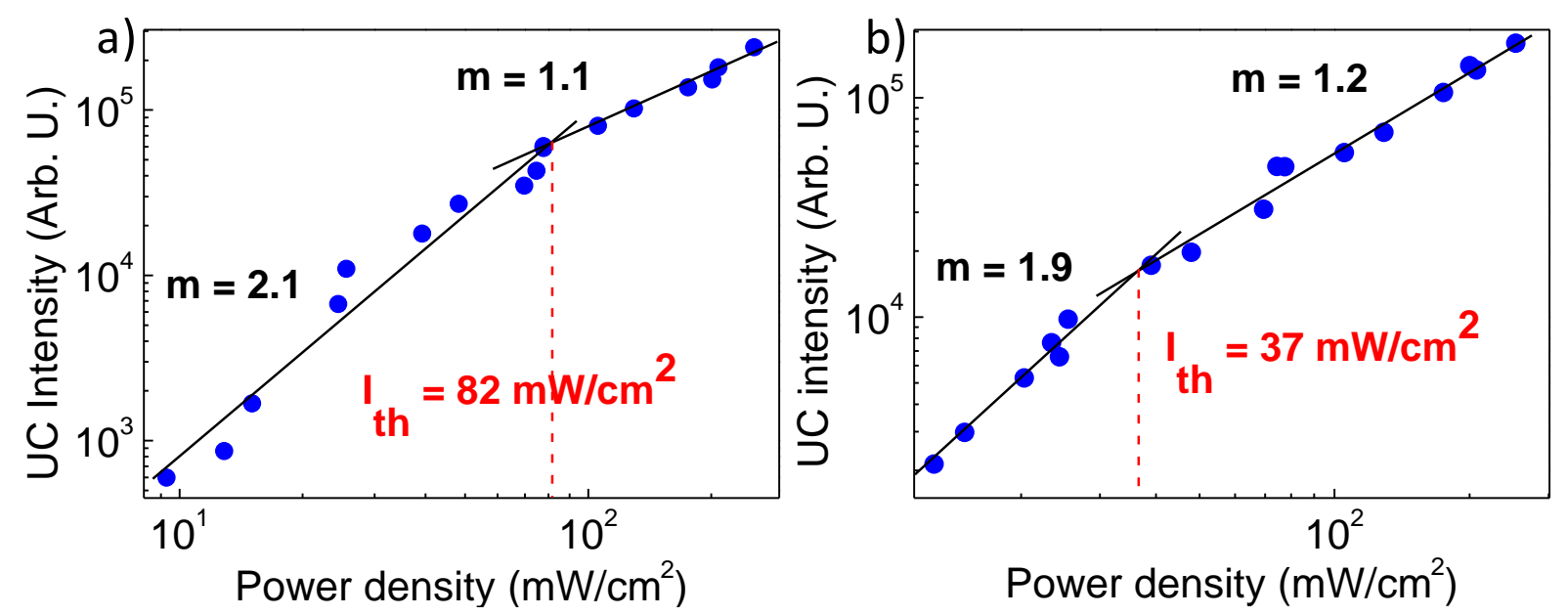

Figure S9. Double logarithmic plots of the integrated UC emission of a PtOEP-DPA mixture in HD ([PtOEP] $=10$ $\mu \mathrm{M} ;[\mathrm{DPA}]=300 \mu \mathrm{M})$ measured at increasing power densities and $\lambda_{\mathrm{exc}}=532 \mathrm{~nm}$ in a) liquid $(\mathrm{T}=293 \mathrm{~K})$ and $\left.\mathrm{b}\right)$ solid $(\mathrm{T}=273 \mathrm{~K})$ state.

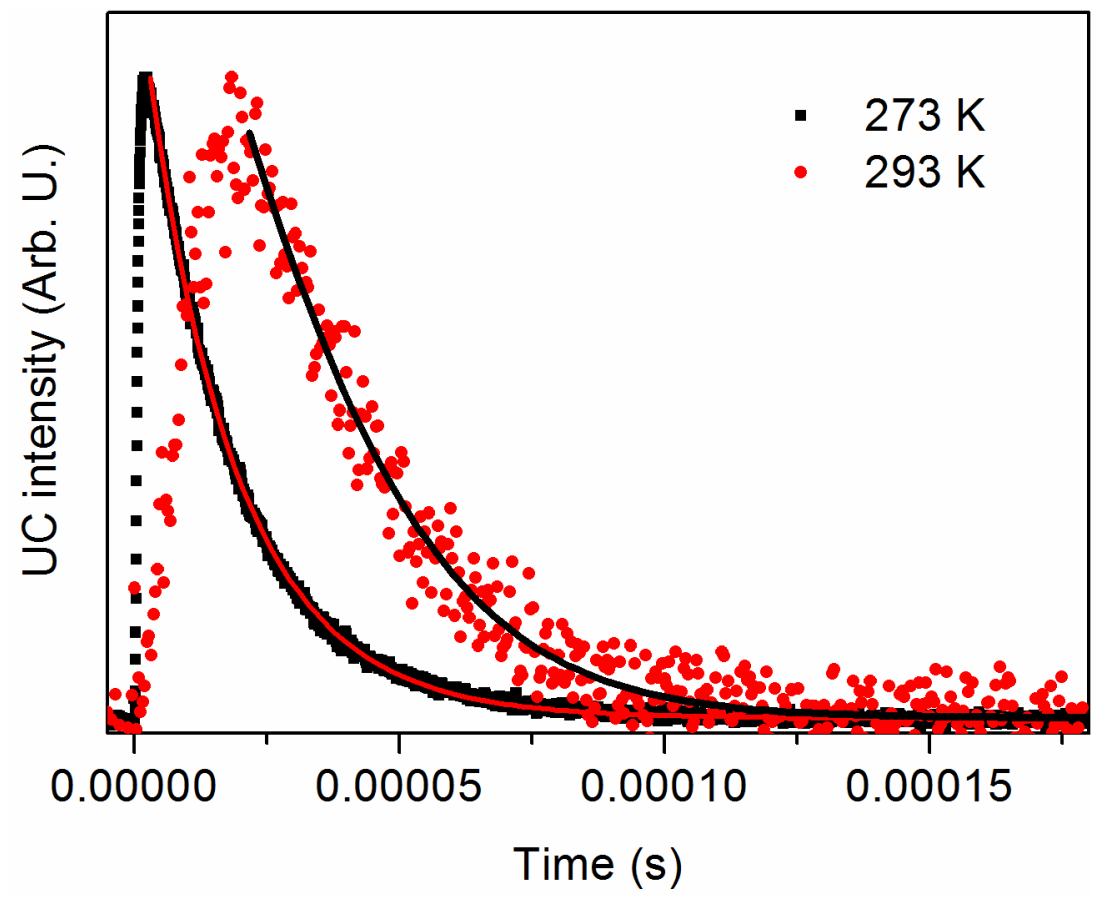

Figure S1o. UC decays measured at $\lambda=433 \mathrm{~nm}$ for a HD solution of PtOEP-DPA ([PtOEP] $=1 \mu \mathrm{M},[\mathrm{DPA}]=30 \mu \mathrm{M})$ in the liquid $(\mathrm{T}=293 \mathrm{~K})$ and solid $(\mathrm{T}=273 \mathrm{~K})$ state. Black squares and red dots correspond to the experimental decays, while solid lines were obtained by fitting equation $S_{1}$ to this data (see Section $\mathrm{S}_{2}$ ). 

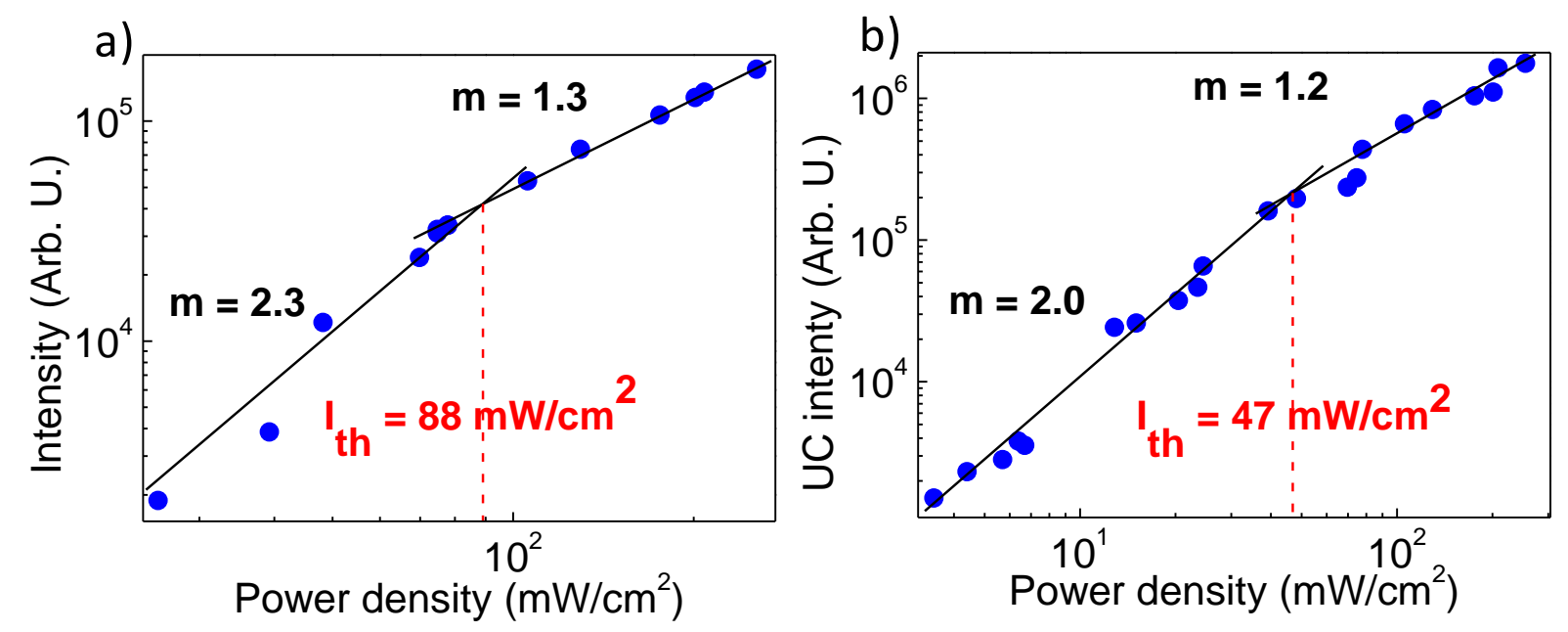

Figure S11. Double logarithmic plots of the integrated UC emission of a PtOEP-DPA mixture in EC ([PtOEP] $=10$ $\mu \mathrm{M} ;[\mathrm{DPA}]=300 \mu \mathrm{M})$ measured at increasing power densities and $\lambda_{\text {exc }}=532 \mathrm{~nm}$ in a) liquid $(\mathrm{T}=323 \mathrm{~K})$ and $\left.\mathrm{b}\right)$ solid $(\mathrm{T}=293 \mathrm{~K})$ state.
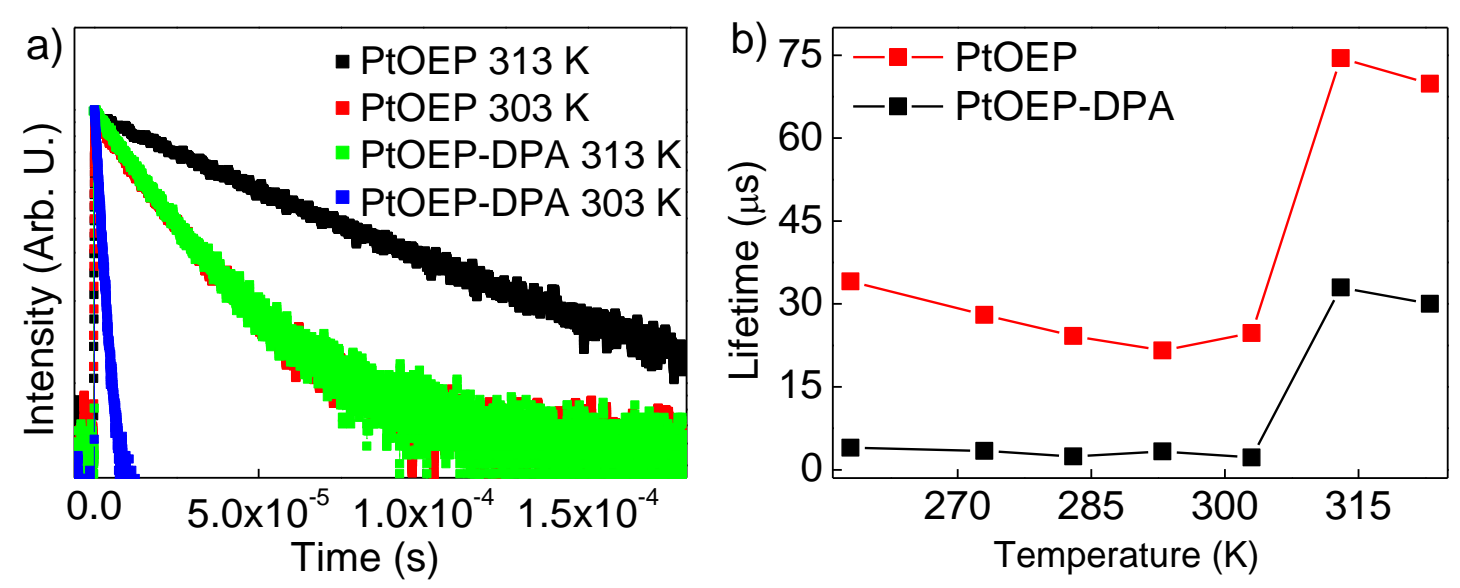

Figure S12. a) Phosphorescence decays at $\lambda=647 \mathrm{~nm}$ of deaerated EC solutions of PtOEP $([\mathrm{PtOEP}]=1 \mu \mathrm{M})$ and PtOEP-DPA $([\mathrm{PtOEP}]=1 \mu \mathrm{M}$; $[\mathrm{DPA}]=30 \mu \mathrm{M})$ measured at $313 \mathrm{~K}$ and $303 \mathrm{~K} . \mathrm{b}) \tau_{\mathrm{T}}$ vs temperature for the EC solutions of PtOEP and PtOEP-DPA. 


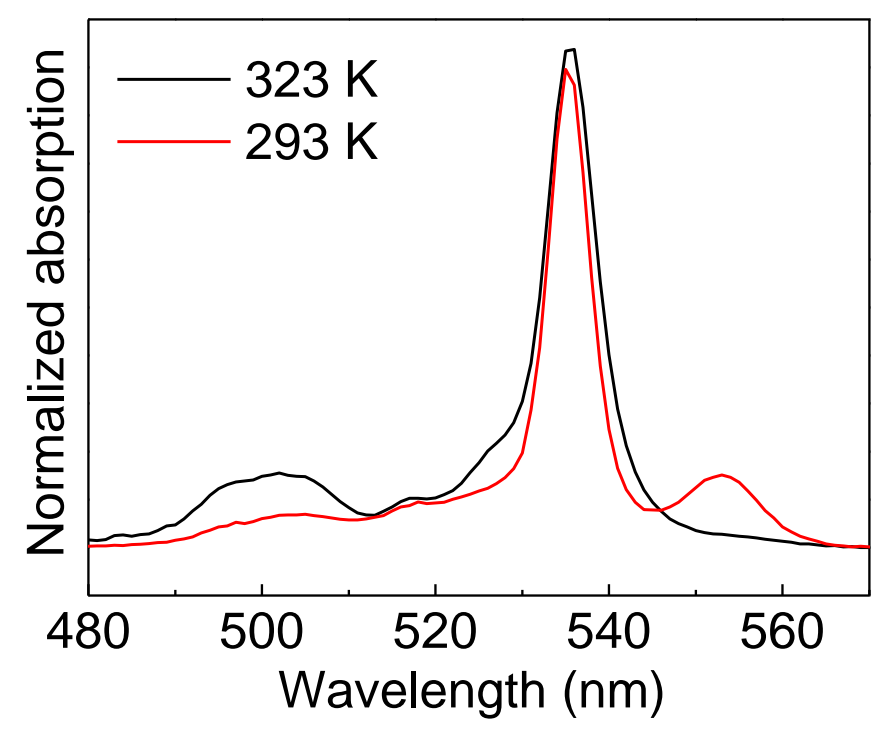

Figure S13. Section of the absorption spectrum of a PtOEP-DPA mixture ([PtOEP] $=10 \mu \mathrm{M},[\mathrm{DPA}]=300 \mu \mathrm{M})$ in liquid $(\mathrm{T}=323 \mathrm{~K})$ and solid $(\mathrm{T}=293 \mathrm{~K}) \mathrm{EC}$. The solid mixture absorption was measured by using the integrating sphere.
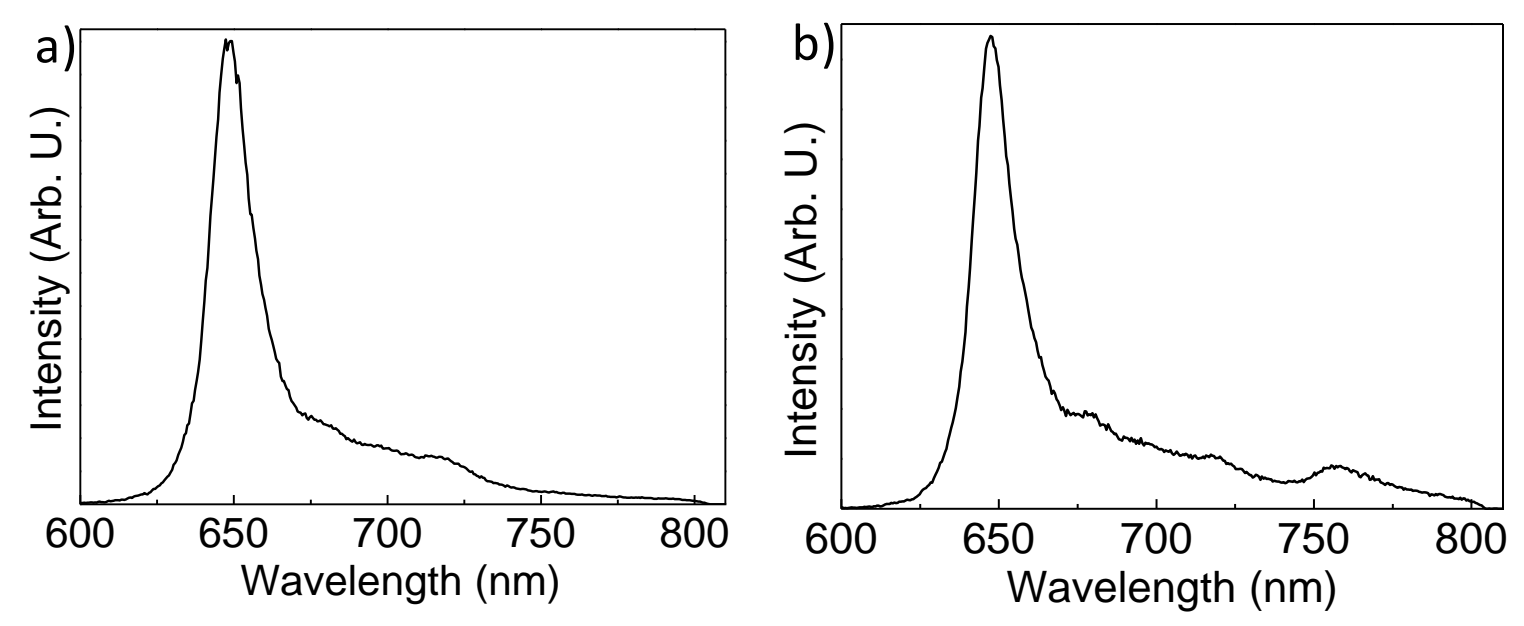

Figure S14. Emission spectra of a deaerated PtOEP solution $([\mathrm{PtOEP}]=10 \mu \mathrm{M})$ in a) liquid $(\mathrm{T}=323 \mathrm{~K})$ and $\mathrm{b})$ solid $(\mathrm{T}=293 \mathrm{~K}) \mathrm{EC}$. 

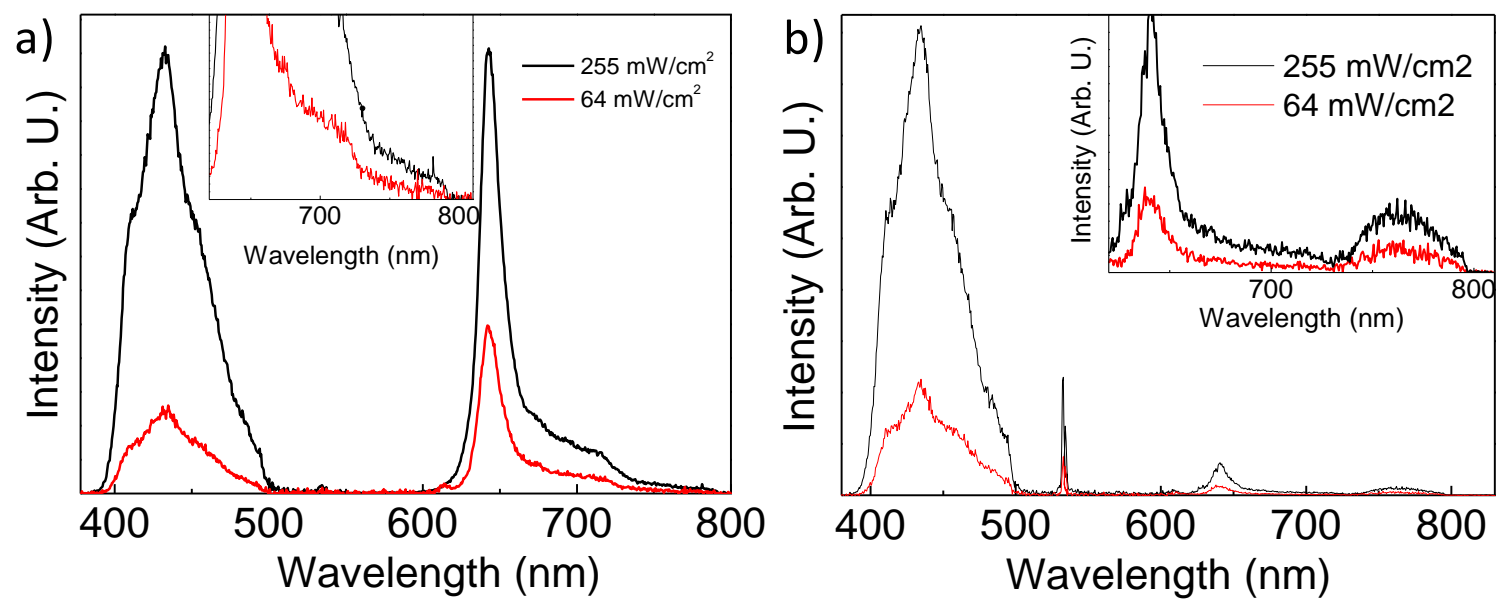

Figure S15. Emission spectra of a deaerated PtOEP-DPA mixture $([\mathrm{PtOEP}]=1 \mu \mathrm{M}$; $[\mathrm{DPA}]=30 \mu \mathrm{M})$ in a) liquid $(\mathrm{T}=$ $323 \mathrm{~K})$ and $\mathrm{b})$ solid $(\mathrm{T}=293 \mathrm{~K}) \mathrm{EC}$ at two different excitation power densities. In the respective insets there are the zooms of the spectra in the range of $630-800 \mathrm{~nm}$.
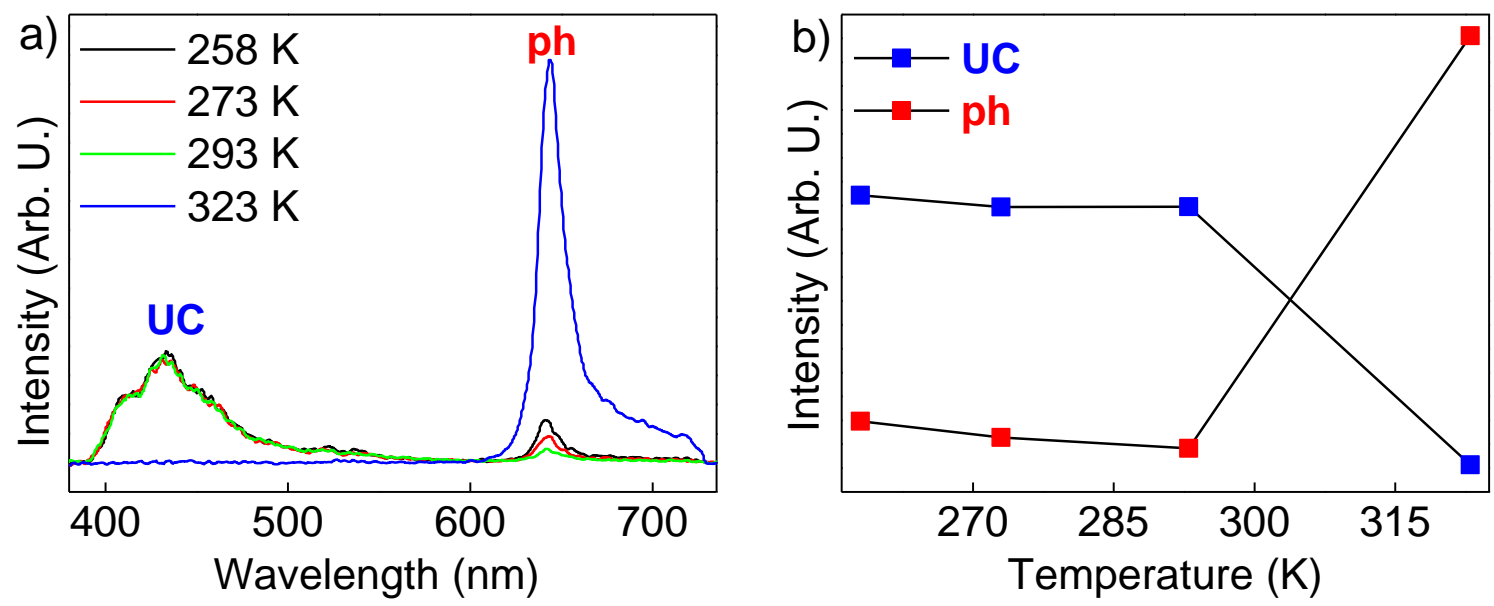

Figure S16. a) UC $\left(\lambda_{\max }=433 \mathrm{~nm}\right)$ and phosphorescence $\left(\lambda_{\max }=647 \mathrm{~nm}\right)$ emissions of a PtOEP-DPA mixture in EC at different temperatures $([\mathrm{PtOEP}]=0.1 \mu \mathrm{M} ;[\mathrm{DPA}]=30 \mu \mathrm{M})$. b) Integrated intensities of the UC and phosphorescence bands for this sample at different temperatures. 

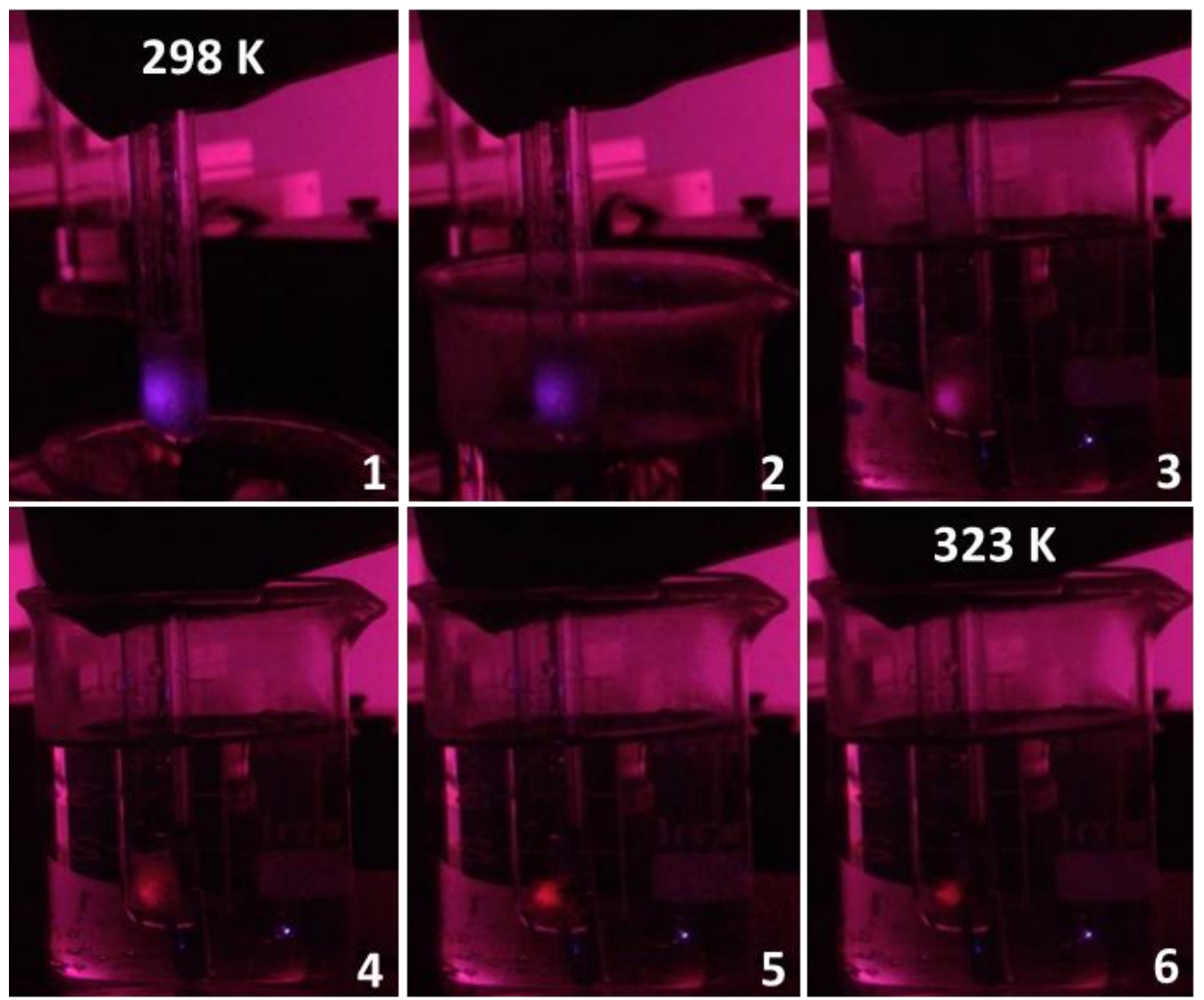

Figure S17. Representative snapshots (1 to 6) of the color change of the PtOEP-DPA mixture in EC during heating $([\mathrm{PtOEP}]=1 \mu \mathrm{M} ;[\mathrm{DPA}]=30 \mu \mathrm{M})$ from room temperature $(298 \mathrm{~K})$ to $323 \mathrm{~K}$. The blue-to-red colour emission change during EC melting can be appreciated in the supported video recorded in real time. The sample was irradiated at $532 \mathrm{~nm}$. Heating was induced by immersing the sample cuvette in a pre-warmed water bath $(323 \mathrm{~K})$.

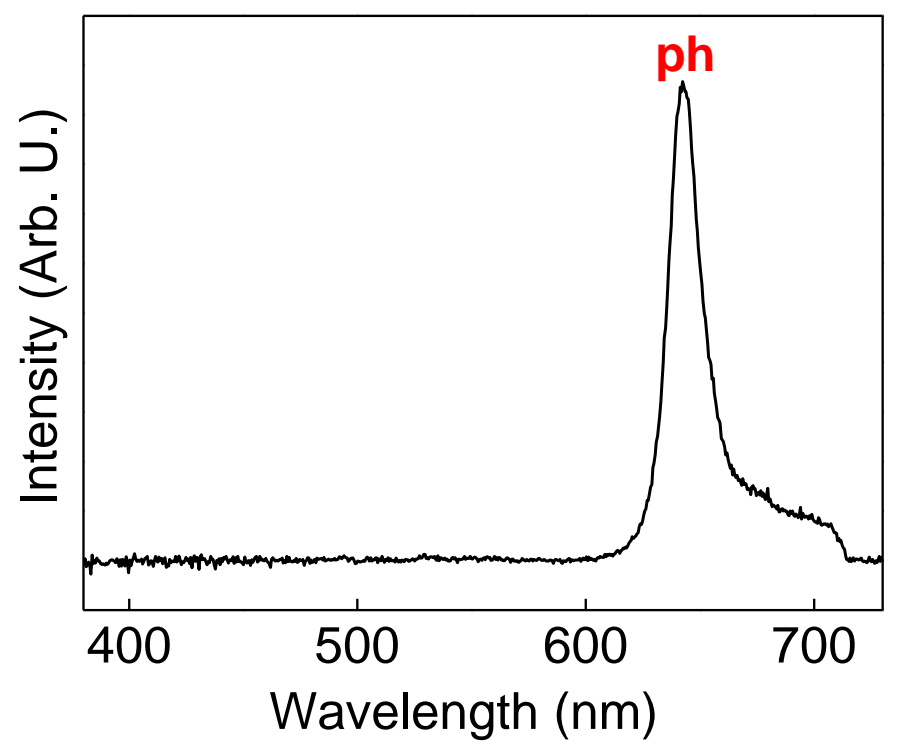

Figure S18. a) Emission spectra of a PMMA polymer film doped with a PtOEP-DPA mixture at $298 \mathrm{~K}$ ([PtOEP] $=1$ $\mu \mathrm{M},[\mathrm{DPA}]=30 \mu \mathrm{M})$. Clearly, no UC emission $\left(\lambda_{\max }=433 \mathrm{~nm}\right)$ was measured at the same concentrations at which this phenomenon was observed for solid HD and EC samples. Instead, only phosphorescence $\left(\lambda_{\max }=647 \mathrm{~nm}\right)$ from the PtOEP sensitizer was registered. 
<smiles>Cc1c2ccccc2c(C)c2ccccc12</smiles><smiles>c1ccc(-c2cc(-c3ccccc3)c3ccc4c(-c5ccccc5)cc(-c5ccccc5)c5ccc2c3c54)cc1</smiles>

\section{DMA}

TPPy

Figure S19. Chemical structures of other investigated TTA-UC pairs. 


\section{a) Fitting of UC emission decays in hexadecane solution}

The UC emission decays in Figure S1o were fitted using equation $\mathrm{Ss}^{1}{ }^{1}$

$$
I_{U C}=I_{0}\left(\frac{1-\beta}{\exp \left(k_{D P A}^{T} t\right)-\beta}\right)^{2}
$$

In this equation $I_{\mathrm{o}}$ stands for the UC emission intensity right after the excitation pulse, $\boldsymbol{k}_{\boldsymbol{D P A} \boldsymbol{A}}^{T}$ is the unimolecular decay rate constant of DPA triplet states ( $\left.{ }^{3} \mathrm{DPA}\right)$, and $\beta$ is a parameter that quantifies the initial fraction of DPA triplet states that decay via triplet-triplet annihilation characterized by the bimolecular rate constant $\boldsymbol{k}_{\text {TTA }}$ :

$\beta=\frac{k_{T T A}\left[{ }^{3} \mathrm{DPA}\right]_{0}}{\boldsymbol{k}_{D P A}^{T}+\boldsymbol{k}_{T T A}\left[{ }^{3} \mathrm{DPA}\right]_{0}}$

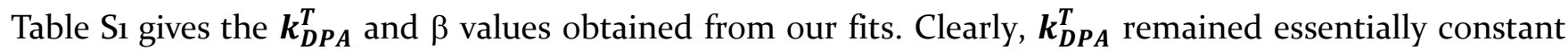
by lowering the temperature and crystallizing the HD solvent, while $\beta$ notably increased indicating a larger contribution of the TTA processes required for UC in the solid matrix.

Table S1. $\boldsymbol{k}_{\boldsymbol{D P A}}^{\boldsymbol{T}}$ and $\beta$ values obtained from fitting the UC emission decays in Figure Sio to equation S1.

\begin{tabular}{|l|l|l|}
\hline Temperature $(\mathrm{K})$ & $\boldsymbol{k}_{\boldsymbol{D P A}}^{T}\left(\mathrm{~s}^{-1}\right)$ & $\boldsymbol{\beta}$ \\
\hline $293 \mathrm{~K}$ & 27212 & 0.0085 \\
\hline $273 \mathrm{~K}$ & 27137 & 0.167 \\
\hline
\end{tabular}

\section{b) Estimation of the HD liquid-to-solid transition in the bimolecular TTA rate constant}

The TTA bimolecular rate constant $\boldsymbol{k}_{\text {TTA }}$ can be determined from the $I_{t h}$ value for UC emission using equation $\mathrm{S}_{3},{ }^{2}$ provided that the corresponding unimolecular decay rate constant $\boldsymbol{k}_{D P A}^{T}$, the quantum yield of the donor-acceptor triplet-triplet energy transfer $\boldsymbol{\Phi}_{\boldsymbol{T T E T}}$, and the absorption coefficient $\boldsymbol{\alpha}(\boldsymbol{E})$ of the donor at the excitation wavelength are known.

$$
I_{t h}=\frac{\left(k_{D P A}^{T}\right)^{2}}{\Phi_{T T E T} \alpha(E) \gamma_{T T A}}
$$

In our case we used equation $\mathrm{S}_{3}$ to estimate the change in $k_{T T A}$ occurring in PtOEP-DPA mixtures in HD upon solvent solidification $\left(k_{T T A}^{273 K} / k_{T T A}^{293} K^{K}\right)$. For this we used the values of $I_{t h}\left(I_{t h}=37\right.$ and $82 \mathrm{~mW} / \mathrm{cm}^{2}$ at 273 and $293 \mathrm{~K}$, respectively), $\Phi_{T T E T}\left(\Phi_{T T E T}=0.97\right.$ and 0.77 at 273 and $293 \mathrm{~K}$, respectively) and $k_{D P A}^{T}\left(k_{D P A}^{T}\right.$ $=27137$ and $27212 \mathrm{~s}^{-1}$ at 273 and $293 \mathrm{~K}$, respectively) previously determined as well as assumed $\alpha(E)$ to negligibly vary along the $273-293 \mathrm{~K}$ thermal range. In this way, we obtained that $k_{T T A}^{273} \mathrm{~K} / k_{T T A}^{293} \mathrm{~K}=1.75$, which clearly indicates that TTA intermolecular processes are also favored in solid HD due to chromophore aggregation. 
1) Cheng, Y. Y.; Fùckel, B.; Khoury, T.; Clady, R. G. C. R.; Tayebjee, M. J. Y.; Ekins-Daukes, N. J.; Crossley, M. J.; Schimidt, T. M. Kinetic Analysis of Photochemical Upconversion by Triplet-Triplet Annihilation: Beyond any Spin Statistical Limit, J. Phys. Chem. Lett. 2010, 1, 1795-1799.

2) Monguzzi, A.; Mezyk, J. Tubino, R.; Meinardi, F. Upconversion-induced Fluorescence in Multicomponent Systems: Steady-state excitation power threshold, Phys. Rev. B 2oo8, 78, 195122. 